EPJ Web of Conferences 45, 01077 (2013)

DOI: $10.1051 /$ epjconf/20134501077

C) Owned by the authors, published by EDP Sciences, 2013

\title{
Coupling of the Models of Human Physiology and Thermal Comfort
}

\author{
J. Pokorny ${ }^{1, a}$ and M. Jicha ${ }^{1}$ \\ ${ }^{1}$ Brno University of Technology, Faculty of Mechanical Engineering, Energy Institute, Technicka 2896/2, Brno, \\ Czech Republic, pokorny.j@fme.vutbr.cz
}

\begin{abstract}
A coupled model of human physiology and thermal comfort was developed in Dymola/Modelica. A coupling combines a modified Tanabe model of human physiology and thermal comfort model developed by Zhang. The Coupled model allows predicting the thermal sensation and comfort of both local and overall from local boundary conditions representing ambient and personal factors. The aim of this study was to compare prediction of the Coupled model with the Fiala model prediction and experimental data. Validation data were taken from the literature, mainly from the validation manual of software Theseus-FE [1]. In the paper validation of the model for very light physical activities $(1 \mathrm{met})$ indoor environment with temperatures from $12{ }^{\circ} \mathrm{C}$ up to $48{ }^{\circ} \mathrm{C}$ is presented. The Coupled model predicts mean skin temperature for cold, neutral and warm environment well. However prediction of core temperature in cold environment is inaccurate and very affected by ambient temperature. Evaluation of thermal comfort in warm environment is supplemented by skin wettedness prediction. The Coupled model is designed for non-uniform and transient environmental conditions; it is also suitable simulation of thermal comfort in vehicles cabins. The usage of the model is limited for very light physical activities up to 1.2 met only.
\end{abstract}

\section{Introduction}

Thermal comfort is by definition "condition of mind that expresses satisfaction with the thermal environment" [2]. Thermal comfort is easy to feel, but hard to predict, because it is subjective quantity which differs for every person. By the ISO standards from Ergonomics of the thermal environment, a prediction of thermal comfort is not individual, but it is predicted for an average human or as average sensation of large group of people. For buildings environment is commonly used ISO 7730: Analytical determination and interpretation of thermal comfort using calculation of the PMV and PPD indices and local thermal comfort criteria [3]. For vehicle cabins (especially car cabin environment) is recommended to use ISO 14505-2: Evaluation of thermal environments in vehicles - Part 2: Determination of equivalent temperature [4]. However both ISO standards are designed only for stationary environmental conditions.

For specific application in army, medicine and clothing industry applications are used model of human physiology to predict human thermal responses. This type of models can be also used for thermal comfort application if the empirical model of thermal sensation is applied. One of the most well known thermal comfort model based on the human physiology is the Fiala model coupled with the Fiala's index DTS [5], which expresses dynamical thermal sensation using the same scale as the
PMV index. Streblow [6] used coupling of the Tanabe [7] and the Zhang model [8] to evaluate thermal comfort in airplanes. Streblow optimized and calibrated a coupled model (Tanabe and Zhang) to fit votes from a large set of questionnaires, which were filled by people during a flight.

This paper presents coupling of the modified Tanabe model of human physiology with the revisited thermal comfort model by Zhang [9-11].

\section{Methods}

\subsection{Model of human physiology}

The Tanabe model is a 16 segmented physiological model based on the Stolwijk model; it represents an average man of the weight $74.43 \mathrm{~kg}$ and the DuBois area $1.87 \mathrm{~m}^{2}$. The human physiology model is split into two parts: the passive and the active system. The first one describes heat transfer in human and on its surface; the second one describes control signals that affect regulatory responses: shivering, vasoconstriction, vasodilatation and sweating. The rate of thermoregulatory responses depends on the actual deviation of core and skin temperatures from the set point temperatures.

Each segment consists of four concentric tissue layers, where one differential heat balance equation is 
calculated for each tissue layer of each segment (equation 1 - core, 2 - muscle, 3 - fat, 4 - skin). The produced metabolic heat flow $\dot{Q}_{m}$ is transferred through tissues by conduction $\dot{Q}_{d}$ and also by the blood flow $\dot{Q}_{b}$. The heat exchange with environment is given by respiration $\dot{Q}_{r e s}^{(2,1)}$ (it is considered only from chest core), evaporation $\dot{Q}_{e}$ and dry heat loss through clothing $\dot{Q}_{c l}$. If there is any segment completely in contact with the ambient surface then instead of equation 5 will be $\dot{Q}_{c l}^{(i)}=\dot{Q}_{\text {contact }}^{(i)}$. Other heat flows as $\dot{Q}_{c}^{(i)}$ convection, $\dot{Q}_{r}^{(i)}$ radiation and $\dot{Q}_{e}^{(i)}$ evaporation are then equal to zero.

$$
\begin{gathered}
C^{(i, 1)} \cdot \frac{d T^{(i, 1)}}{d t}=\dot{Q}_{m}^{(i, 1)}-\dot{Q}_{b}^{(i, 1)}-\dot{Q}_{d}^{(i, 1)}-\dot{Q}_{r e s}^{(i, 1)}, \\
C^{(i, 2)} \cdot \frac{d T^{(i, 2)}}{d t}=\dot{Q}_{m}^{(i, 2)}-\dot{Q}_{b}^{(i, 2)}+\dot{Q}_{d}^{(i, 1)}-\dot{Q}_{d}^{(i, 2)}, \\
C^{(i, 3)} \cdot \frac{d T^{(i, 3)}}{d t}=\dot{Q}_{m}^{(i, 3)}-\dot{Q}_{b}^{(i, 3)}-\dot{Q}_{d}^{(i, 2)}-\dot{Q}_{d}^{(i, 3)}, \\
C^{(i, 4)} \cdot \frac{d T^{(i, 4)}}{d t}=\dot{Q}_{m}^{(i, 4)}-\dot{Q}_{b}^{(i, 4)}+\dot{Q}_{d}^{(i, 3)}-\dot{Q}_{e}^{(i)}-\dot{Q}_{c l}^{(i)}, \\
\dot{Q}_{c l}^{(i)}=\dot{Q}_{c}^{(i)}+\dot{Q}_{r}^{(i)}-\dot{Q}_{s r}^{(i)},
\end{gathered}
$$

where indexes ${ }^{(i, j)}$ mean $\mathrm{i}$-th segment, $\mathrm{j}$-th layer and $C$ is heat capacity of tissues, $\mathrm{W} \cdot \mathrm{h} /{ }^{\circ} \mathrm{C}$.

The original Tanabe model was slightly modified. Local heat transfer coefficients were taken from [12] instead of constant coefficients. In the model, temperature of both the arterial and the venous blood for each particular segment were considered instead of one blood temperature of the central blood compartment as was in the original model. Moreover the counter-current heat exchange between arteries and veins is estimated in the similar way as in the Fiala model [5].

\subsection{Model of thermal comfort}

The Zhang model is an empirical model that comes from regression analysis of 109 human tests realized at the University of Berkeley. The model was validated for car cabin environments in 64 tests, which were carried out at Delphi climate chamber in Lockport, NY, USA. The model evaluates four quantities: local thermal sensation, overall thermal sensation, local thermal comfort, and overall thermal comfort, see figure 1. Zhang used extended 9-point scale for the thermal sensation $(+4$ very hot; 0 neutral; -4 very cold) and for the thermal comfort (+4 very comfortable; $0+$ just comfortable; 0 - just uncomfortable; -4 very uncomfortable). The local thermal sensation is evaluated from the 19 measured points at the skin surface and from the measurement of the core temperature respectively. The local thermal sensation is a basic subjective quantity that determines the overall sensation, the local comfort, and the overall comfort. After validation measurements Zhang published the revisited model [9-11] that correlates better with the experimental data. In the revision of the model was improved an evaluation of the overall thermal sensation. The weighted approach was replaced by the algorithm, which takes into account the effect of opposite sensations more precisely, see figure 2 .

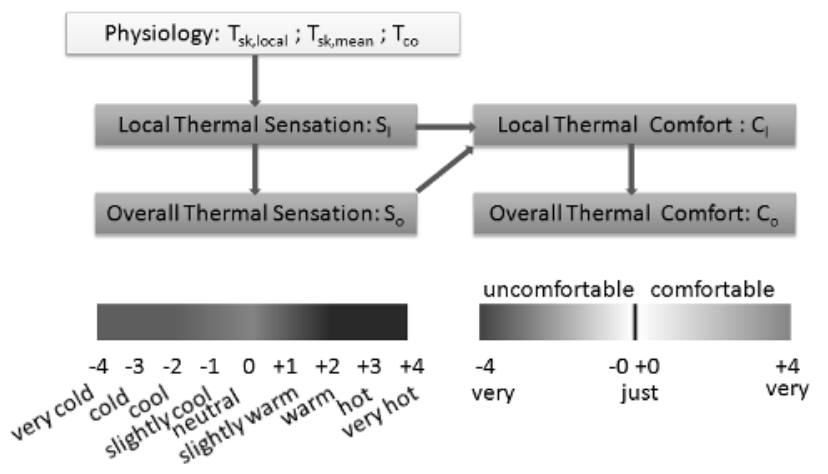

Fig. 1. The scheme of thermal comfort model by Zhang with the scales of thermal sensation (left side) and comfort (right side).

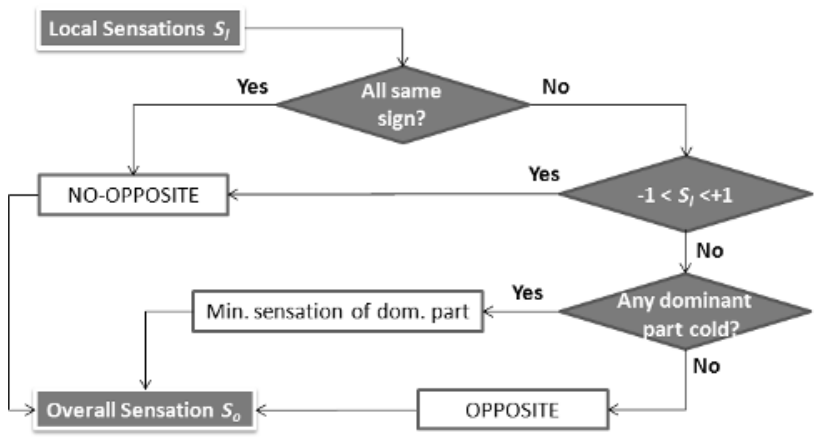

Fig. 2. The scheme of the algorithm which evaluates overall thermal sensation from local thermal sensations.

\subsection{Coupling of the models}

The modified Tanabe and Zhang model were coupled with the following assumptions:

- The breath, face and neck sectors of Zhang model are coupled with the head segment of Tanabe model.

- The mean skin temperature was calculated as the average value over area of individual segments (in the Zhang model the mean skin temperature was measured by the 7-point DuBois method which is considered to be equivalent).

- The Zhang model considered core temperature and its effect on dynamical thermal sensation for the central body parts (face, chest, back and pelvis). In the Coupled model the influence of core temperature is neglected due to the fact that the prediction of the core temperature by the modified Tanabe model is inaccurate see figure 5 .

- Local skin temperature representing neutral local sensation in Zhang model was substituted by set point temperatures at neutral state of Tanabe model.

- The Tanabe model is defined in time unit hours and the Zhang model in seconds. From this reason all time derivatives in the Tanabe model was divided by 3600 . 


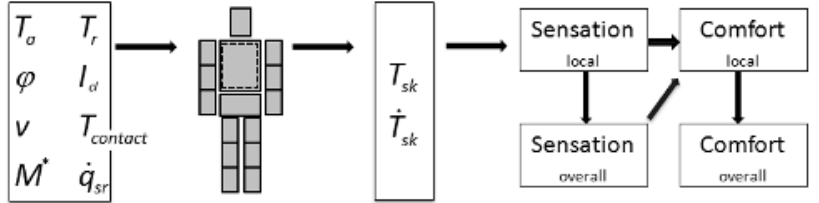

Fig. 3. The scheme of the Coupled model; * means a global parameter.

The Coupled model allows predicting the thermal and the comfort (both local and overall) from the environmental and personal factors see the scheme of the model on the figure 3 . Inputs of the Coupled model are: the ambient air temperature $T_{a}\left({ }^{\circ} \mathrm{C}\right)$, the mean radiant temperature $T_{r}\left({ }^{\circ} \mathrm{C}\right)$, the relative humidity $\varphi(\%)$, the air velocity $v(\mathrm{~m} / \mathrm{s})$, the thermal resistance of clothing $I_{c l}$ (clo), 1 clo $=0.155 \mathrm{~W} \cdot \mathrm{K} / \mathrm{m}^{2}$. Previous quantities must be specified for each particular segment (locally). Moreover the activity level, i.e. global metabolic production $M$ met $\left(1 \mathrm{met}=58.2 \mathrm{~W} / \mathrm{m}^{2}\right)$ must be specified .

\section{Results}

The Coupled model was validated by experimental data from Hardy and Stolwijk, 1966 and Gagge, 1967. They investigated experimentally human thermal state after one hour in indoor environment with the relative humidity $\varphi=30 \%$, the metabolism $M=1$ met, for the maximal air velocity around human surface $v=0.1 \mathrm{~m} / \mathrm{s}$ and the overall thermal resistance of clothing $I_{c l}=0$ clo. Volunteers were dressed only in shorts (local resistance 0.211 clo), which covered only the pelvis area. The emissivity of surrounding environment assumed in simulations equals to 0.93 . The model was tested for the uniform environments with the air and the mean radiant temperature equal to $T_{a}=T_{r}=12{ }^{\circ} \mathrm{C}, 16{ }^{\circ} \mathrm{C}, 20{ }^{\circ} \mathrm{C}$, $24{ }^{\circ} \mathrm{C}, 28{ }^{\circ} \mathrm{C}, 32{ }^{\circ} \mathrm{C}, 36{ }^{\circ} \mathrm{C}, 40{ }^{\circ} \mathrm{C}, 44{ }^{\circ} \mathrm{C}$ and $48{ }^{\circ} \mathrm{C}$. On the figure 4 a comparison of: the predicted mean skin temperature using the Coupled model, the experimental data, and the Fiala model prediction is presented respectively. The predictions are in a very good agreement with the measured data.

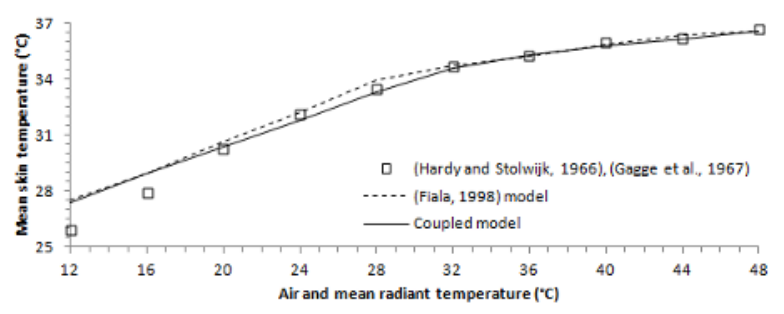

Fig. 4. The comparison of mean skin temperature for various environments.

Main problem of the Coupled model is prediction of the core temperature (rectal) which is good for warm environments, but the predicted core temperature is much lower (difference up to $1{ }^{\circ} \mathrm{C}$ ) for the cold environment. The Fiala model fits the experimental data well in contrary to the Coupled model, see figure 5. The main reason why it fits better is a different definition of the active system. The active system of the Fiala model includes dynamical effect of vasoconstriction.

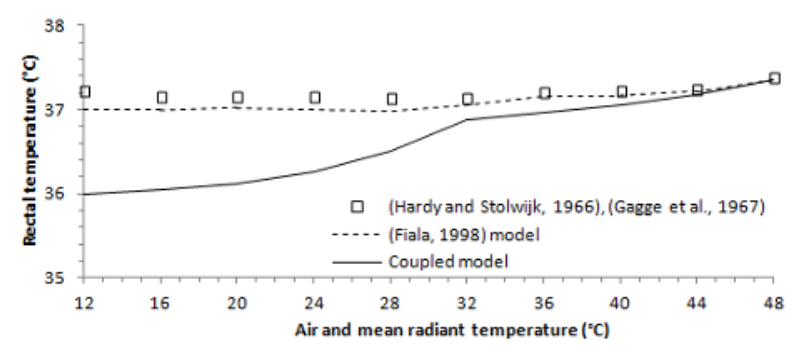

Fig. 5. The comparison of rectal (core) temperature for various environments.

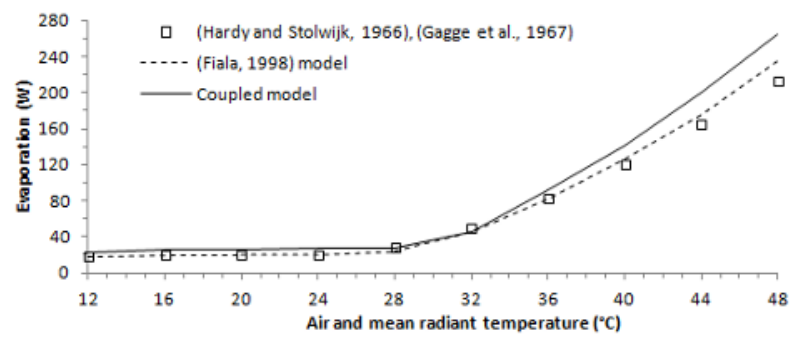

Fig. 6. The comparison of evaporation heat losses for various environments.

The predicted evaporative heat loss is again in a good agreement with the experimental data see figure 6 . In the figure 7 a prediction of both overall thermal sensation and comfort without any experimental comparison is shown. It can be seen that even in a very hot environment the maximal value +4 very hot is not achieved due to the fact that the Zhang model does not considered effect of sweating on thermal sensation and discomfort. The effect of sweating on thermal discomfort can be estimated by a skin wettedness, which is defined as ratio of actual and maximal possible evaporative heat loss. Minimal value of the skin wettedness is $w=0.06$ which implies only diffusive evaporation from the skin. If the sweating occurs then the skin wettedness is increasing. When the skin wettedness exceeds the limit $w=0.3$ then the sweating causes thermal discomfort. The value 0.3 comes from the experimental investigation by Gagge. For example in the figure 7 there is an environment with temperature $36{ }^{\circ} \mathrm{C}$, where overall thermal sensation is +3 and overall thermal comfort is close to 0 . However the overall skin wettedness exceeds limit 0.3 (on the pelvis is about 0.8 ). Interpretation of this result is that human feels hot and not comfortable due to intensive sweating even the overall comfort by the Zhang model is close to 0 .

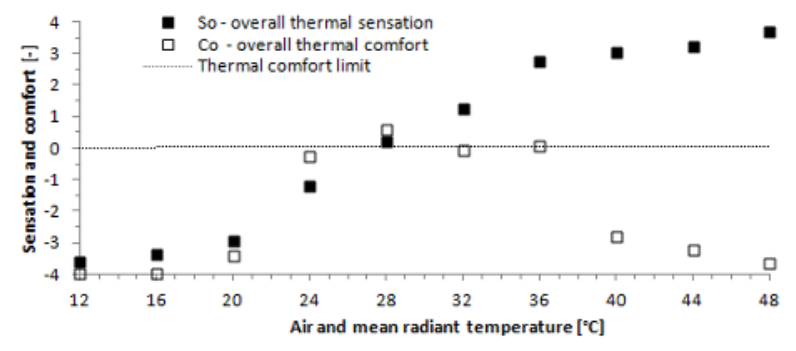

Fig. 7. The evaluation of overall thermal sensation and comfort for various environments. 


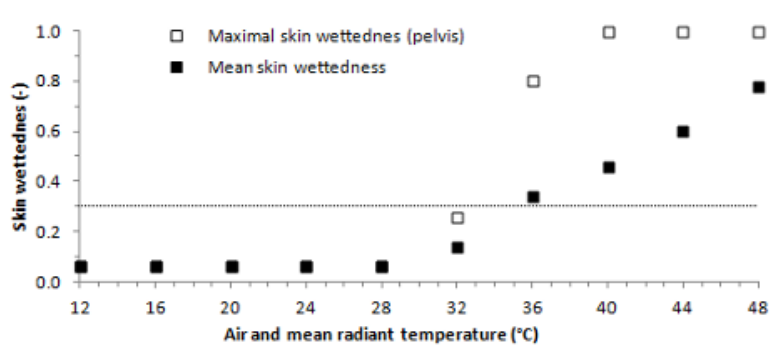

Fig. 8. The evaluation of mean and maximal skin wettedness for various environments.

\section{Conclusion}

In Modelica/Dymola the Coupled model of human physiology and thermal comfort was created, which coupled the modified Tanabe model and the Zhang model. In this paper results of the model validation for stationary and uniform environmental conditions from $12{ }^{\circ} \mathrm{C}$ to $48^{\circ} \mathrm{C}$ and for the very light physical activity 1 met were shown. However the model is also designed for transient and non-uniform environmental conditions. The predictions of the Coupled model were compared with the experimental data and also with the predictions of Fiala model. The mean skin temperature was predicted well, the local skin temperature was predicted with lower accuracy, and the core temperature was predicted inaccurately in cold environments. From this reason the effect of core temperature on the thermal comfort was neglected. In the original Zhang model the effect of sweating on thermal comfort is neglected, which limits usage of the model for warm and hot environments. To solve this problem, the thermal comfort predicted by the Coupled model was associated also with a rate of perspiration, which can be evaluated by the skin wettedness. To identify discomfort threshold caused by skin wettedness, Gagge criteria $w<0.3$ was adopted.

The comparison of results confirm that coupling of the modified Tanabe and the Zhang model is a convenient way how to predict thermal comfort. Even through some modifications the Coupled model is a good tool for prediction of thermal comfort in transient and non-uniform conditions. There is one restriction in usage of the model. The coupled model is not recommended to use for high level of physical activities, the recommended maximal value is $1.2 \mathrm{met}$, i.e. very light activities in seated posture. However this restriction does not limit the model to be used in car cabin environments.

\section{Acknowledgement}

Financial support from the projects of the Brno University of Technology FSI-S-11-6 is gratefully acknowledged.

\section{References}

1. $\mathrm{P}+\mathrm{Z}$, Theseus-FE. Validations Version 4.0. Munich (2011)
2. ASHRAE, ASHRAE Handbook Fundamentals, Atlanta, USA (2001)

3. ČSN EN ISO 7730 - Ergonomie tepelného prostředí - Analytické stanovení a interpretace tepelného komfortu pomocí výpočtu ukazatelů PMV a PPD a kritéria místního tepelného komfortu (2005)

4. ČSN EN ISO 14505-2 - Ergonomie tepelného prostředí - Hodnocení tepelného prostředí ve vozidlech - Část 2: Stanovení ekvivalentní teploty (2007)

5. Fiala, D. Dynamic simulation of human heat transfer and thermal comfort. Ph.D. Thesis, Institute of Energy and Sustainable Development. Leicester, De Montfort University (1998)

6. Streblow, R. Thermal Sensation and Comfort Model for Inhomogeneous Indoor Environments. Ph.D. Thesis, Fakultät für Maschinenwesen. Technischen Hochschule Aachen (2010)

7. Tanabe, S., Kobayashi, K., Nakano, J., Ozeki, Y. and Konishi, M., Evaluation of thermal comfort using combined multi-node thermoregulation $(65 \mathrm{MN})$ and radiation models and computational fluid dynamics (CFD). Energy and Buildings, 34, 6, 637-646 (2002)

8. Zhang, H., Human thermal sensation and comfort in transient and non-uniform thermal environments, $\mathrm{PhD}$ thesis, University of California Berkeley (2003)

9. Zhang, H., Arens, E., Huizenga, C. and Han, T., Thermal sensation and comfort models for nonuniform and transient environments: Part I: Local sensation of individual body parts. Building and Environment, 45, 2, 380-388 (2010)

10. Zhang, H., Arens, E., Huizenga, C. and Han, T., Thermal sensation and comfort models for nonuniform and transient environments, part II: Local comfort of individual body parts. Building and Environment, 45, 2, 389-398 (2010)

11. Zhang, H., Arens, E., Huizenga, C. and Han, T., Thermal sensation and comfort models for nonuniform and transient environments, part III: Wholebody sensation and comfort. Building and Environment, 45, 2, 399-410 (2010)

12. Nilsson, H.O. Comfort Climate Evaluation with Thermal Manikin Methods and Computer Simulation Models. Ph.D. Thesis, University of Gävle. (2004) 